\title{
First Enantioselective Total Synthesis and Structure Determination of the Anthrapyran Metabolite Y-Indomycinone
}

\author{
Lutz F. Tietze*, Ramakrishna Reddy Singidi, and Kersten M. Gericke \\ ${ }^{[*}$ Institute of Organic und Biomolecular Chemistry, Georg-August-University, Tammannstr. 2, D-37077 \\ Göttingen, Germany: Phone: +49-(0)551-393271, Fax: +49-(0)551-399476, E-mail: ltietze@gwdg.de
}

\section{Experimental Section}

General: All reactions were performed under an argon atmosphere in flame-dried flasks and the reactants were introduced by syringe. All solvents were dried by standard methods. All reagents obtained from commercial sources were used without further purification. Thin-layer chromatography was performed on precoated silica gel plates (SIL G/UV 254 , Macherey-Nagel GmbH \& Co. KG). Silica gel 60 (0.032-0.064 $\mathrm{mm})$ (Merck) was used for column chromatography. UV/Vis spectra $\left(\mathrm{CH}_{3} \mathrm{CN}\right)$ : Mettler Lambda 2 spectrometer. IR spectra (KBr pellets or films): Bruker Vector 22 spectrometer. ${ }^{1} \mathrm{H}$ and ${ }^{13} \mathrm{C}$ NMR spectra: Varian Mercury 300, Unity 300 or Inova 600 spectrometer with tetramethylsilane (TMS) as the internal standard in chloroform-d. Mass spectra at (70 eV): Finnigan MAT95.

\section{Compound 13:}

To a stirred suspension of LAH ( $48 \mathrm{mg}, 1.3 \mathrm{mmol})$ in dry THF $(4 \mathrm{~mL})$ at $0^{\circ} \mathrm{C}$ was added a solution the ester $12(390 \mathrm{mg}, 1.3 \mathrm{mmol})$ in anhydrous THF $(2.5 \mathrm{~mL})$ and stirring was continued at the same temperature for 30 min. The reaction mixture was diluted with diethyl ether and quenched by adding ice pieces. The reaction mixture was passed through a small pad of celite and the filtrate evaporated under reduced pressure to afford the crude product which was purified by column chromatography using $15 \%$ EtOAc/pentane as the eluent to yield the alcohol $13(201 \mathrm{mg}, 1.04 \mathrm{mmol})$ in 80\% yield as viscous oil. ${ }^{1} \mathrm{H}$ NMR $\left(300 \mathrm{MHz}, \mathrm{CDCl}_{3}\right) \delta 0.93(\mathrm{t}, J=7.4 \mathrm{~Hz}, 3 \mathrm{H}), 1.23(\mathrm{~s}, 3 \mathrm{H}), 1.59-1.70(\mathrm{~m}, 2 \mathrm{H}), 1.78-2.02(\mathrm{bs}, 1 \mathrm{H})$, $3.47(\mathrm{~d}, J=11.6 \mathrm{~Hz}, 1 \mathrm{H}), 3.58(\mathrm{~d}, J=11.6 \mathrm{~Hz}, 1 \mathrm{H}), 4.43(\mathrm{~s}, 2 \mathrm{H}), 7.28-7.37(\mathrm{~m}, 5 \mathrm{H}) .{ }^{13} \mathrm{C} \mathrm{NMR}(125 \mathrm{MHz}$, $\left.\mathrm{CDCl}_{3}\right) \delta 8.07,19.56,27.75,63.57,66.94,77.92,127.39,128.38,139.10 .[\alpha]_{\mathrm{D}}+2.6\left(c 0.5, \mathrm{CHCl}_{3}\right) . \mathrm{IR}$ $(\mathrm{KBr}): \widetilde{v}=3418,2925,1455,1067 . \mathrm{UV}\left(\mathrm{CH}_{3} \mathrm{CN}\right): \lambda_{\max }(\lg \varepsilon)=251.5$ (2.378), 257.5 (2.396), 362.5 (3.622). MS (EI), m/z: $217.1[\mathrm{M}+\mathrm{Na}]^{+}, 165.1,163.1,91.1$.

\section{Compound 14:}

To a stirred solution of IBX (436 mg, $1.56 \mathrm{mmol})$ in DMSO (1.5 mL) was added of solution of 13 (200 $\mathrm{mg}, 1.04 \mathrm{mmol}$ ) in $4.0 \mathrm{ml} \mathrm{CH}_{2} \mathrm{Cl}_{2}$. The reaction mixture was stirred at r.t. for $8 \mathrm{~h}$ and quenched by the addition of an aq. saturated $\mathrm{Na}_{2} \mathrm{~S}_{2} \mathrm{O}_{3}$ solution. The aq. layer was extracted with $\mathrm{CH}_{2} \mathrm{Cl}_{2}$ and the organic 
layer washed with aq. saturated $\mathrm{NaHCO}_{3}$ solution, water, brine and dried over $\mathrm{Na}_{2} \mathrm{SO}_{4}$. The solvent was evaporated under reduced pressure to afford the crude product which was purified by chromatography using 12\% EtOAc/pentane as the eluent to yield compound 14 (183 $\mathrm{mg}, 0.95 \mathrm{mmol})$ in $92 \%$ yield as a liquid. ${ }^{1} \mathrm{H} \mathrm{NMR}\left(300 \mathrm{MHz}, \mathrm{CDCl}_{3}\right) \delta 0.85(\mathrm{t}, J=8.0 \mathrm{~Hz}, 3 \mathrm{H}), 1.23(\mathrm{~s}, 3 \mathrm{H}), 1.62(\mathrm{~d}, \mathrm{q}, J=10.5,8.0 \mathrm{~Hz}$, $1 \mathrm{H}), 1.73(\mathrm{~d}, \mathrm{q}, J=10.5,8.0 \mathrm{~Hz}, 1 \mathrm{H}), 4.35$ (d, $J=11.4 \mathrm{~Hz}, 1 \mathrm{H}), 4.40$ (d, $J=11.4 \mathrm{~Hz}, 1 \mathrm{H}), 7.27-7.31$ (m, 5H), 9.57 (s, 1H). ${ }^{13} \mathrm{C}$ NMR $\left(75 \mathrm{MHz}, \mathrm{CDCl}_{3}\right) \delta 7.26,17.64,27.68,66.04,82.86,127.38,127.63,128.38$, 138.25, 205.23. $[\alpha]_{\mathrm{D}}+26.4\left(c 1.3, \mathrm{CHCl}_{3}\right)$. IR $(\mathrm{KBr}): \widetilde{v}=1734,1455,1384,1160,1067, \mathrm{UV}\left(\mathrm{CH}_{3} \mathrm{CN}\right)$ : $\lambda_{\max }(\lg \varepsilon)=257.5(2.424), 263.0$ (2.348). Ms (EI) 215.1 (M + Na $\left.{ }^{+}\right), 192.1,163.1,91.1,55.0$.

\section{Compound 15:}

To a stirred mixture of $\mathrm{CBr}_{4}(628 \mathrm{mg}, 1.9 \mathrm{mmol})$ and zinc $(123 \mathrm{mg}, 1.9 \mathrm{mmol})$ in $\mathrm{CH}_{2} \mathrm{Cl}_{2}(1.5 \mathrm{~mL})$ at $0^{\circ} \mathrm{C}$

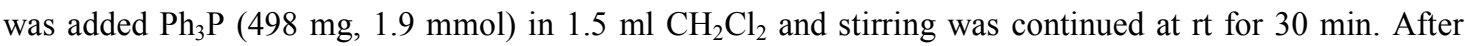
cooling back to $0^{\circ} \mathrm{C}$ a solution of the aldehyde $14(183 \mathrm{mg}, 0.95 \mathrm{mmol})$ in $2 \mathrm{~mL} \mathrm{CH}_{2} \mathrm{Cl}_{2}$ was added. The reaction mixture was stirred at r.t. for $6 \mathrm{~h}$ and then diluted with pentane with vigorous stirring. A precipitate is formed which was removed by filtration through Florisil. The filtrate was evaporated under reduced pressure to afford the crude product which was purified by chromatography using 5\% EtOAc/pentane as the eluent to yield compound 15 (277 mg, $0.79 \mathrm{mmol})$ in $84 \%$ yield as a liquid. ${ }^{1} \mathrm{H}$ NMR (300 MHz, $\left.\mathrm{CDCl}_{3}\right) \delta 0.95(\mathrm{t}, J=7.7 \mathrm{~Hz}, 3 \mathrm{H}), 1.46(\mathrm{~s}, 3 \mathrm{H}), 1.78(\mathrm{~d}, \mathrm{q}, J=13.2,7.7 \mathrm{~Hz}, 1 \mathrm{H}), 1.89$ (d, q, $J=13.2,7.7$ $\mathrm{Hz}, 1 \mathrm{H}), 4.38(\mathrm{~d}, J=10.7 \mathrm{~Hz}, 1 \mathrm{H}), 4.43(\mathrm{~d}, J=10.7 \mathrm{~Hz}, 1 \mathrm{H}), 6.65(\mathrm{~s}, 1 \mathrm{H}), 7.24-7.38(\mathrm{~m}, 5 \mathrm{H}) .{ }^{13} \mathrm{C}$ NMR $\left(75 \mathrm{MHz}, \mathrm{CDCl}_{3}\right) \delta 7.94,22.56,31.81,64.77,79.75,88.10,127.30,127.47,128.28,138.86,142.45 .[\alpha]_{\mathrm{D}}+$ 1.7(c 1.0, $\left.\mathrm{CHCl}_{3}\right)$. IR (KBr): $\widetilde{v}=2973,1594,1454,1381,1064$. Ms (EI) 322.0, 319.0, 198.9, 144.1, 91.1, 65.0 .

\section{Compound 4:}

To a stirred solution of compound $15(277 \mathrm{mg}, 0.79 \mathrm{mmol})$ in dry THF $(3 \mathrm{~mL})$ at $-78^{\circ} \mathrm{C}$ was added $n$-BuLi ( $2.4 \mathrm{M}$ in hexane, $0.69 \mathrm{~mL}, 1.66 \mathrm{mmol}$ ). After being warmed to $-20^{\circ} \mathrm{C}$ over $2 \mathrm{~h}$, the mixture was recooled to $-78^{\circ} \mathrm{C}$ and DMF $(0.05 \mathrm{~mL})$ was added. After being gradually warmed to $\mathrm{rt}$ over $3 \mathrm{~h}$, the mixture was quenched by the addition of aq. saturated $\mathrm{NH}_{4} \mathrm{Cl}$ solution. The reaction mixture was diluted with diethyl ether and washed with water, brine and dried over $\mathrm{Na}_{2} \mathrm{SO}_{4}$. The solvent was evaporated under reduced pressure to afford the crude product which was purified by column chromatography. Elution with $10 \%$ EtOAc/pentane provided product $4(136 \mathrm{mg}, 0.63 \mathrm{mmol})$ in $80 \%$ yield as a colorless liquid. ${ }^{1} \mathrm{H}$ NMR (300 $\left.\mathrm{MHz}, \mathrm{CDCl}_{3}\right) \delta 1.05(\mathrm{t}, J=7.1 \mathrm{~Hz}, 3 \mathrm{H}), 1.54(\mathrm{~s}, 3 \mathrm{H}), 1.79-1.91(\mathrm{~m}, 2 \mathrm{H}), 4.59(\mathrm{~d}, J=10.7 \mathrm{~Hz}, 1 \mathrm{H}), 4.64(\mathrm{~d}$, $J=10.7 \mathrm{~Hz}, 1 \mathrm{H}), 7.22-7.34(\mathrm{~m}, 5 \mathrm{H}), 9.25(\mathrm{~s}, 1 \mathrm{H}) .{ }^{13} \mathrm{C} \mathrm{NMR}\left(125 \mathrm{MHz}, \mathrm{CDCl}_{3}\right) \delta 8.45,25.10,33.93$, $66.71,74.10,84.87,97.61,127.49,127.54,128.33,138.29,176.50 .[\alpha]_{\mathrm{D}}-5.6\left(c\right.$ 0.34, $\left.\mathrm{CHCl}_{3}\right) . \mathrm{IR}(\mathrm{KBr}): \widetilde{v}$ $=1713,1454,1382,1275,1065$. Ms (EI) 215.1, 203.1, 159.1, 105.0, 91.1, 65.0. 


\section{Compound 16:}

To a stirred solution of compound $3(123 \mathrm{mg}, 0.25 \mathrm{mmol})$ in dry THF $(1.5 \mathrm{~mL})$ at $-78^{\circ} \mathrm{C}$ was added $n$ BuLi (2.5 $\mathrm{M}$ in hexane, $0.11 \mathrm{~mL}, 0.27 \mathrm{mmol})$ followed by propargylic aldehyde $4(65 \mathrm{mg}, 0.3 \mathrm{mmol})$ dissolved in THF $(0.5 \mathrm{~mL})$. Stirring was continued at $-78^{\circ} \mathrm{C}$ for $10 \mathrm{~min}$ and the reaction was quenched by the addition of aq. saturated $\mathrm{NH}_{4} \mathrm{Cl}$ solution. The reaction mixture was diluted with $\mathrm{CH}_{2} \mathrm{Cl}_{2}$ and washed with water, brine and dried over $\mathrm{Na}_{2} \mathrm{SO}_{4}$. The solvent was evaporated under reduced pressure to afford the crude product which was purified by column chromatography. Elution with 15\% EtOAc/pentane provided product $16(135 \mathrm{mg}, 0.21 \mathrm{mmol})$ in 86\% yield as a viscous oil. ${ }^{1} \mathrm{H} \mathrm{NMR}\left(300 \mathrm{MHz}, \mathrm{CDCl}_{3}\right) \delta 0.93-1.05(\mathrm{~m}$, $6 \mathrm{H}), 1.12-1.48(\mathrm{~m}, 18 \mathrm{H}), 1.67-1.85(\mathrm{~m}, 4 \mathrm{H}), 2.63-2.88(\mathrm{bs}, 6 \mathrm{H}), 3.71(\mathrm{~s}, 6 \mathrm{H}), 4.04(\mathrm{~s}, 6 \mathrm{H}), 4.51-4.70(\mathrm{~m}$, $6 \mathrm{H}), 5.19-5.32(\mathrm{bs}, 4 \mathrm{H}), 6.20-6.65(\mathrm{bs}, 2 \mathrm{H}), 6.82-6.88(\mathrm{~m}, 2 \mathrm{H}), 7.19-7.47(\mathrm{~m}, 20 \mathrm{H}), 7.63-7.70(\mathrm{~m}, 2 \mathrm{H})$, 7.79-7.87 (m, 4H). ${ }^{13} \mathrm{C}$ NMR $\left(500 \mathrm{MHz}, \mathrm{CDCl}_{3}\right) \delta 8.69,25.70,34.36,34.40,62.64,63.61,66.27,71.33$, $74.27,77.51,87.21,106.24,115.12,119.03,125.73,127.17,127.22,127.53,127.64,128.19,128.36$, 137.44, 139.13, 139.14, 146.92, 150.51, 156.28. IR (KBr): $\widetilde{v}=3443,2976,1728,1593,1454,1381,1299$, 1042. UV $\left(\mathrm{CH}_{3} \mathrm{CN}\right): \lambda_{\max }(\lg \varepsilon)=268.5$ (4.120), 295.5 (3.679), 361.5 (3.089), 380.0 (3.194), 396.0 (3.112), 419.0 (2.980). Ms (ESI) 203.2, 558.1, 512.1.

\section{Compound 17:}

To a stirred solution of compound $16(126 \mathrm{mg}, 0.2 \mathrm{mmol})$ in dioxan (4 mL) was added AgO (124 mg, 1 mmol) followed by $4 \mathrm{~N} \mathrm{HNO}_{3}$ until the silver oxide has completely dissolved. The resulting solution was stirred for $30 \mathrm{~min}$ and then diluted with $\mathrm{CH}_{2} \mathrm{Cl}_{2}$. The organic layer was washed with water, brine, dried over $\mathrm{Na}_{2} \mathrm{SO}_{4}$ and the solvent evaporated under reduced pressure to afford the crude product which was purified by chromatography using 30\% EtOAc/pentane as the eluent to yield compound 17 (108 mg, 0.18 $\mathrm{mmol})$ in $90 \%$ yield as a viscous oil. ${ }^{1} \mathrm{H}$ NMR $\left(300 \mathrm{MHz}, \mathrm{CDCl}_{3}\right) \delta$ 0.93-1.02 (m, 6H), 1.23-1.36 (m, 12H), $1.44(\mathrm{~s}, 3 \mathrm{H}), 1.45(\mathrm{~s}, 3 \mathrm{H}), 1.69-1.82(\mathrm{~m}, 4 \mathrm{H}), 2.69$ (s, 6H), 3.05-3.14 (bs, 2H), 4.32-4.44 (m, 2H), 4.51-4.61 $(\mathrm{m}, 4 \mathrm{H}), 5.61-5.29(\mathrm{~s}, 4 \mathrm{H}), 6.28(\mathrm{~s}, 1 \mathrm{H}), 6.29(\mathrm{~s}, 1 \mathrm{H}), 7.19-7.45(\mathrm{~m}, 18 \mathrm{H}), 7.59-7.67(\mathrm{~m}, 6 \mathrm{H}), 7.79-7.86(\mathrm{~m}$, $4 \mathrm{H}) .{ }^{13} \mathrm{C}$ NMR $\left(125 \mathrm{MHz}, \mathrm{CDCl}_{3}\right) \delta 8.66,20.48,22.27,22.40,25.62,25.63,34.31,34.35,58.20,58.23$, $66.21,66.22,70.91,74.18,79.22,84.32,84.39,87.62,119.40,119.63,124.89,126.52,126.66,126.75$, $127.25,127.36,127.38,127.83$, 128.20, 128.47, 133.49, 133.97, 134.92, 136.33, 139.0, 139.01, 139.82, 139.84, 144.25, 144.27, 154.60, 157.92, 183.25, 183.31. IR (KBr): $\widetilde{v}=2922,1670,1452,1266,1029$. UV $\left(\mathrm{CH}_{3} \mathrm{CN}\right): \lambda_{\max }(\lg \varepsilon)=258.5$ (4.264), 381.5 (3.620). MS (ESI): $623.2[\mathrm{M}+\mathrm{Na}]^{+}, \mathrm{HRMS}$ for $\mathrm{C}_{39} \mathrm{H}_{38} \mathrm{O}_{6}$ $[\mathrm{M}+\mathrm{H}]^{+}: 603.27412$ (cal); 603.27404 (found)

\section{Compound 18:}

To a stirred solution of IBX $(63 \mathrm{mg}, 0.22 \mathrm{mmol})$ in DMSO $(0.25 \mathrm{~mL})$ was added compound $17 \mathrm{in} 0.8 \mathrm{ml}$ $\mathrm{CH}_{2} \mathrm{Cl}_{2}(90 \mathrm{mg}, 0.15 \mathrm{mmol})$. The mixture was stirred at r.t. for $5 \mathrm{~h}$ and quenched by addition of an aq. saturated $\mathrm{Na}_{2} \mathrm{~S}_{2} \mathrm{O}_{3}$ solution. The aq. layer was extracted with $\mathrm{CH}_{2} \mathrm{Cl}_{2}$ and the organic layer washed with aq. 
saturated $\mathrm{NaHCO}_{3}$ solution, water, brine, dried over $\mathrm{Na}_{2} \mathrm{SO}_{4}$ and the solvent evaporated under reduced pressure. The obtained crude product which was purified by chromatography using $20 \%$ EtOAc/pentane as the eluent to yield compound 18 (83 mg, $0.14 \mathrm{mmol})$ in $93 \%$ yield as a viscous oil. ${ }^{1} \mathrm{H} \mathrm{NMR} \mathrm{(300} \mathrm{MHz}$, $\left.\mathrm{CDCl}_{3}\right) \delta 1.05(\mathrm{t}, J=7.4 \mathrm{~Hz}, 3 \mathrm{H}), 1.29-132(\mathrm{~m}, 6 \mathrm{H}), 1.55(\mathrm{~s}, 3 \mathrm{H}), 1.81-1.94(\mathrm{~m}, 2 \mathrm{H}), 2.41(\mathrm{~s}, 3 \mathrm{H}), 4.41-$ $4.53(\mathrm{~m}, 1 \mathrm{H}), 4.60(\mathrm{~d}, J=10.4 \mathrm{~Hz}, 1 \mathrm{H}), 4.66(\mathrm{~d}, J=10.4 \mathrm{~Hz}, 1 \mathrm{H}), 5.27$ (s, 2H), 7.15-7.42 (m, 9H), 7.58$7.66(\mathrm{~m}, 3 \mathrm{H}), 7.81-7.86(\mathrm{~m}, 2 \mathrm{H}) .{ }^{13} \mathrm{C} \mathrm{NMR}\left(125 \mathrm{MHz}, \mathrm{CDCl}_{3}\right) \delta 8.53,19.60,22.21,22.22,24.97,33.93$, $66.81,70.87,74.30,79.14,85.67,97.02,119.44,119.82,123.96,124.62,126.50,126.63,127.35,127.59$, $127.80,128.21,128.46,134.03,134.78,136.28,138.41,141.42,141.66,155.61,158.07,180.79,182.15$, 183.19. $[\alpha]_{\mathrm{D}}-4.8\left(c \mathrm{0} 0.8, \mathrm{CHCl}_{3}\right)$. IR $(\mathrm{KBr}): \widetilde{v}=2978,2934,2206,1673,1585,1444,1281,1063 . \mathrm{UV}$ $\left(\mathrm{CH}_{3} \mathrm{CN}\right): \lambda_{\max }(\lg \varepsilon)=259.0(4.431), 377.0$ (2.887). MS (ESI): $623.3[\mathrm{M}+\mathrm{Na}]^{+}, 599.1[\mathrm{M}-\mathrm{H}]^{+}, \mathrm{HRMS}$ for $\mathrm{C}_{39} \mathrm{H}_{36} \mathrm{O}_{6}[\mathrm{M}+\mathrm{H}]^{+}: 601.25847$ (cal); 601.25872 (found).

\section{Compound 2:}

To a stirred solution of compound $18(70 \mathrm{mg}, 0.12 \mathrm{mmol})$ in $\mathrm{AcOH}(2.5 \mathrm{~mL})$ was added $\mathrm{H}_{2} \mathrm{SO}_{4}(0.01 \mathrm{~mL})$ at $\mathrm{rt}$ and stirring was continued at $55^{\circ} \mathrm{C}$ for $30 \mathrm{~min}$. The mixture was diluted with $\mathrm{CH}_{2} \mathrm{Cl}_{2}$ and the organic layer washed with water and brine. Drying and evaporation under reduced pressure afforded the crude product which was purified by chromatography using $10 \%$ EtOAc/pentane as the eluent to yield compound $2(47 \mathrm{mg}, 0.1 \mathrm{mmol})$ in $88 \%$ yield as a viscous oil. ${ }^{1} \mathrm{H}$ NMR $\left(300 \mathrm{MHz}, \mathrm{CDCl}_{3}\right) \delta 1.07(\mathrm{t}, J=7.4 \mathrm{~Hz}, 3 \mathrm{H})$, 1.57 (s, 3H), 1.78-1.96 (m, 2H), 2.47 (s, 3H), 4.61 (d, $J=11.2 \mathrm{~Hz}, 1 \mathrm{H}), 4.67$ (d, $J=11.2 \mathrm{~Hz}, 1 \mathrm{H}), 7.14-$ $7.33(\mathrm{~m}, 6 \mathrm{H}), 7.65-7.73(\mathrm{~m}, 2 \mathrm{H}), 7.82(\mathrm{dd}, J=7.4,1.3 \mathrm{~Hz}, 1 \mathrm{H}), 11.90(\mathrm{~s}, 1 \mathrm{H}), 12.41(\mathrm{~s}, 1 \mathrm{H}) . .{ }^{13} \mathrm{C}$ NMR $\left(125 \mathrm{MHz}, \mathrm{CDCl}_{3}\right) \delta 8.55,20.42,25.0,33.97,66.80,74.47,85.43,97.11,114.20,115.64,120.22,121.97$, $124.92,127.32,127.40,128.21,133.24,133.59,134.01,137.40,138.46,146.66,160.38,162.50,178.40$, 181.23, 192.29. $[\alpha]_{\mathrm{D}}-16.3\left(c 0.9, \mathrm{CHCl}_{3}\right)$. IR $(\mathrm{KBr}): \widetilde{v}=2923,1649,1451,1267,1028 . \mathrm{UV}\left(\mathrm{CH}_{3} \mathrm{CN}\right)$ : $\lambda_{\max }(\lg \varepsilon)=257.5$ (4.372), 426.5 (3.937), $570.0(2.821) . \mathrm{MS}(\mathrm{ESI}): 491.2[\mathrm{M}+\mathrm{Na}]^{+}, 467.4[\mathrm{M}+\mathrm{H}]^{+}$, HRMS for $\mathrm{C}_{29} \mathrm{H}_{24} \mathrm{O}_{6}[\mathrm{M}+\mathrm{Na}]^{+}: 491.14651$ (cal); 491.14641 (found).

\section{Compound 19:}

To a stirred solution of compound $2(37 \mathrm{mg}, 0.08 \mathrm{mmol})$ in acetone $(2 \mathrm{~mL})$ at $0^{\circ} \mathrm{C}$ was added $\mathrm{Cs}_{2} \mathrm{CO}_{3}(25$ $\mathrm{mg}, 0.08 \mathrm{mmol}$ ). The reaction mixture was brought to room temperature over $30 \mathrm{~min}$, then diluted with diethyl ether and filtered through a small pad of celite. The filtrate was evaporated under reduced pressure to afford the crude product which was purified by column chromatography using $10 \%$ EtOAc/pentane as the eluent to provide compound 19 (24 mg, $0.05 \mathrm{mmol})$ in $65 \%$ yield as a viscous oil. ${ }^{1} \mathrm{H}$ NMR $(300 \mathrm{MHz}$, $\left.\mathrm{CDCl}_{3}\right) \delta 0.94(\mathrm{t}, J=7.3 \mathrm{~Hz}, 3 \mathrm{H}), 1.57(\mathrm{~s}, 3 \mathrm{H}), 2.12-2.21(\mathrm{~m}, 2 \mathrm{H}), 3.02(\mathrm{~s}, 3 \mathrm{H}), 4.54(\mathrm{~d}, J=10.7 \mathrm{~Hz}, 1 \mathrm{H})$, $4.59(\mathrm{~d}, J=10.7 \mathrm{~Hz}, 1 \mathrm{H}), 6.66(\mathrm{~s}, 1 \mathrm{H}), 7.28-7.43(\mathrm{~m}, 6 \mathrm{H}), 7.69(\mathrm{t}, J=7.6 \mathrm{~Hz}, 1 \mathrm{H}), 7.83(\mathrm{dd}, J=7.6,1.4$ $\mathrm{Hz}, 1 \mathrm{H}), 8.07$ (s, $1 \mathrm{H}), 12.92(\mathrm{~s}, 1 \mathrm{H}) .{ }^{13} \mathrm{C} \mathrm{NMR}\left(125 \mathrm{MHz}, \mathrm{CDCl}_{3}\right) \delta 7.96,21.84,24.21,31.23,64.78$, $79.04,111.22,116.74,119.29,119.81,125.29,125.60,126.45,127.10,127.46,128.37,132.18,135.93$, 
$136.31,138.26,149.79,156.31,162.54,170.63,179.20,181.83,187.10 .[\alpha]_{\mathrm{D}}+7.0\left(c 0.2, \mathrm{CHCl}_{3}\right) . \mathrm{IR}$ $(\mathrm{KBr}): \widetilde{v}=2923,1651,1461,1266,1027 . \mathrm{UV}\left(\mathrm{CH}_{3} \mathrm{CN}\right): \lambda_{\max }(\lg \varepsilon)=239.5$ (4.222), 265.5 (4.027), 418.0 (3.515). MS (ESI): 467.3 [M-H] $]^{+}$, HRMS for $\mathrm{C}_{29} \mathrm{H}_{24} \mathrm{O}_{6}[\mathrm{M}+\mathrm{H}]^{+}: 469.16456$ (cal); 469.16434 (found).

\section{Compound 1:}

To a stirred solution of compound $19(18 \mathrm{mg}, 0.04 \mathrm{mmol})$ in $\mathrm{CH}_{2} \mathrm{Cl}_{2}(0.8 \mathrm{~mL})$ at $-78^{\circ} \mathrm{C}$ was added $\mathrm{TiCl}_{4}(1$ $\mathrm{M}$ in $\mathrm{CH}_{2} \mathrm{Cl}_{2}, 0.2 \mathrm{~mL}, 0.2 \mathrm{mmol}$ ) and the mixture was allowed to warm to $-20^{\circ} \mathrm{C}$ over $3 \mathrm{~h}$. Then, the mixture was diluted with $\mathrm{CH}_{2} \mathrm{Cl}_{2}$, washed successively with $1 \mathrm{M} \mathrm{HCl}$, water, brine and dried over $\mathrm{Na}_{2} \mathrm{SO}_{4}$. The solvent was evaporated under reduced pressure to afford the crude product which was purified by column chromatography on silica gel using 40\% EtOAc/pentane as the eluent to yield compound 1 (12 mg, $0.03 \mathrm{mmol})$ in $85 \%$ yield. ${ }^{1} \mathrm{H} \mathrm{NMR}\left(300 \mathrm{MHz}, \mathrm{CDCl}_{3}\right) \delta 0.97(\mathrm{t}, J=7.5 \mathrm{~Hz}, 3 \mathrm{H}), 1.67(\mathrm{~s}, 3 \mathrm{H}), 1.98(\mathrm{~d}, \mathrm{q}, J=$ 14.2, $7.5 \mathrm{~Hz}, 1 \mathrm{H}), 2.10$ (d, q, $J=14.2,7.5 \mathrm{~Hz}, 1 \mathrm{H}), 2.85(\mathrm{~s}, 1 \mathrm{H}), 3.03(\mathrm{~s}, 3 \mathrm{H}), 6.52(\mathrm{~s}, 1 \mathrm{H}), 7.37$ (dd, $J=$ 8.3, $1.2 \mathrm{~Hz}, 1 \mathrm{H}), 7.69$ (t, $J=7.9 \mathrm{~Hz}, 1 \mathrm{H}), 7.83(\mathrm{dd}, J=7.5,1.2 \mathrm{~Hz}, 1 \mathrm{H}), 8.0(\mathrm{~s}, 1 \mathrm{H}), 12.83(\mathrm{~s}, 1 \mathrm{H}) .{ }^{1} \mathrm{H}$ NMR (300 MHz, DMSO-d6) $\delta 0.84(\mathrm{t}, J=7.6 \mathrm{~Hz}, 3 \mathrm{H}), 1.61(\mathrm{~s}, 3 \mathrm{H}), 1.85(\mathrm{~d}, \mathrm{q}, J=13.4,7.6 \mathrm{~Hz}, 1 \mathrm{H}), 2.07$ $(\mathrm{d}, \mathrm{q}, J=13.4,7.6 \mathrm{~Hz}, 1 \mathrm{H}), 2.92(\mathrm{~s}, 3 \mathrm{H}), 5.47(\mathrm{~s}, 1 \mathrm{H}), 6.49(\mathrm{~s}, 1 \mathrm{H}), 7.41(\mathrm{dd}, J=8.8,1.2 \mathrm{~Hz}, 1 \mathrm{H}), 7.71(\mathrm{dd}$ $, J=7.6,1.2 \mathrm{~Hz}, 1 \mathrm{H}), 7.79(\mathrm{t}, J=8.9 \mathrm{~Hz}, 1 \mathrm{H}), 7.96(\mathrm{~s}, 1 \mathrm{H}), 12.66-12.76(\mathrm{bs}, 1 \mathrm{H}) .{ }^{13} \mathrm{C} \mathrm{NMR}(500 \mathrm{MHz}$, DMSO-d6) $\delta 7.72,23.30,26.58,32.85,72.59,108.95,116.67,118.59,119.71,124.59,124.62,125.52$, $132.05,135.69,136.51,148.24,155.55,161.36,173.75,178.24,186.91 .[\alpha]_{\mathrm{D}}+4.0(c 0.1$, DMSO). IR $(\mathrm{KBr}): \widetilde{v}=3365,2921,2851,1722,1674,1650,1461,1314,1265,1189 . \mathrm{UV}(\mathrm{MeOH}): \lambda_{\max }(\lg \varepsilon)=$ 204.5 (3.961), 239.0 (4.072), 267.0 (3.811), 419.0 (3.306). MS (ESI): $379.1[\mathrm{M}+\mathrm{H}]^{+}, \mathrm{HRMS}$ for $\mathrm{C}_{29} \mathrm{H}_{18} \mathrm{O}_{6}$ $[\mathrm{M}+\mathrm{H}]^{+}: 379.11761$ (cal); 379.11799 (found). 


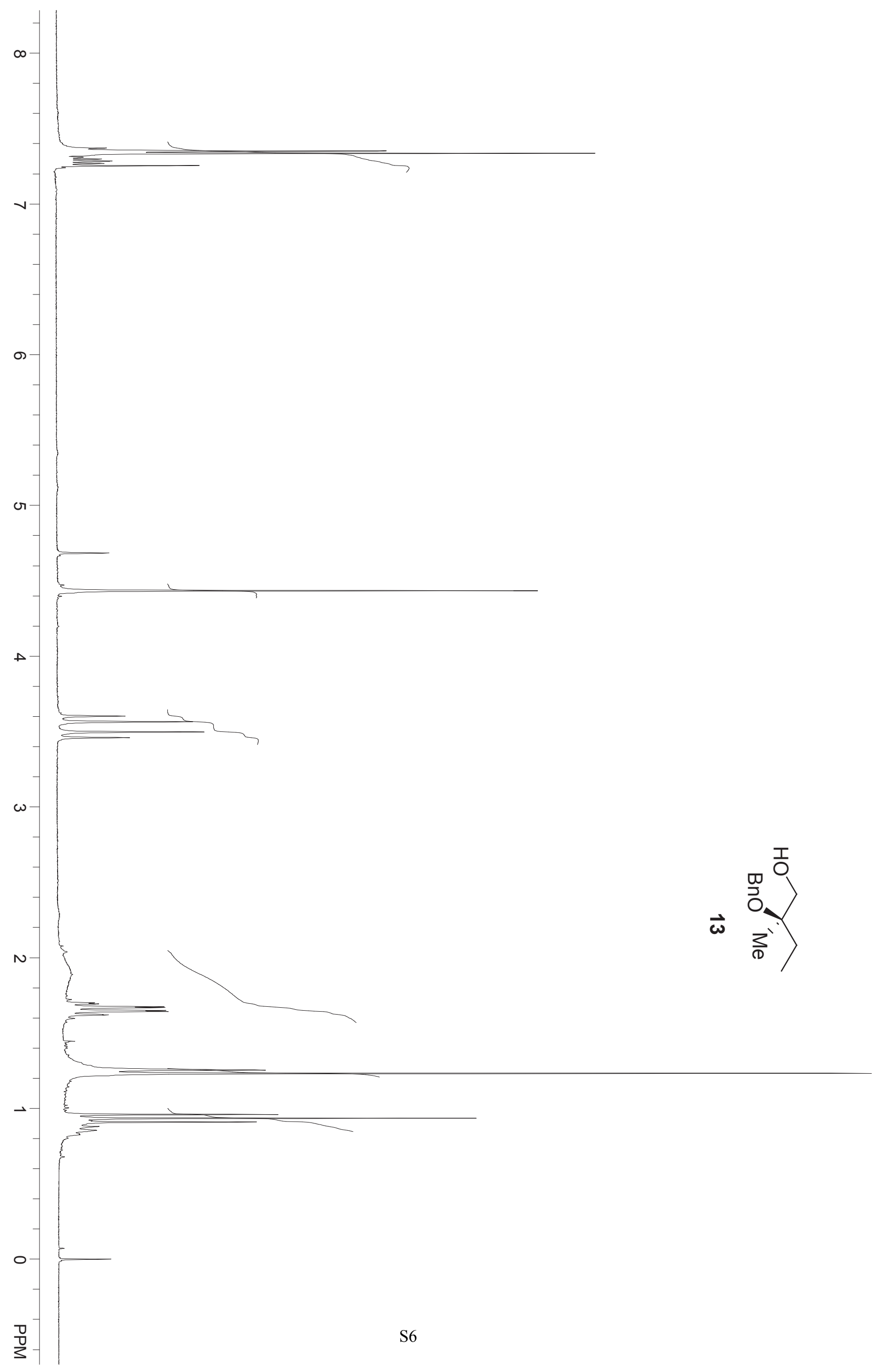




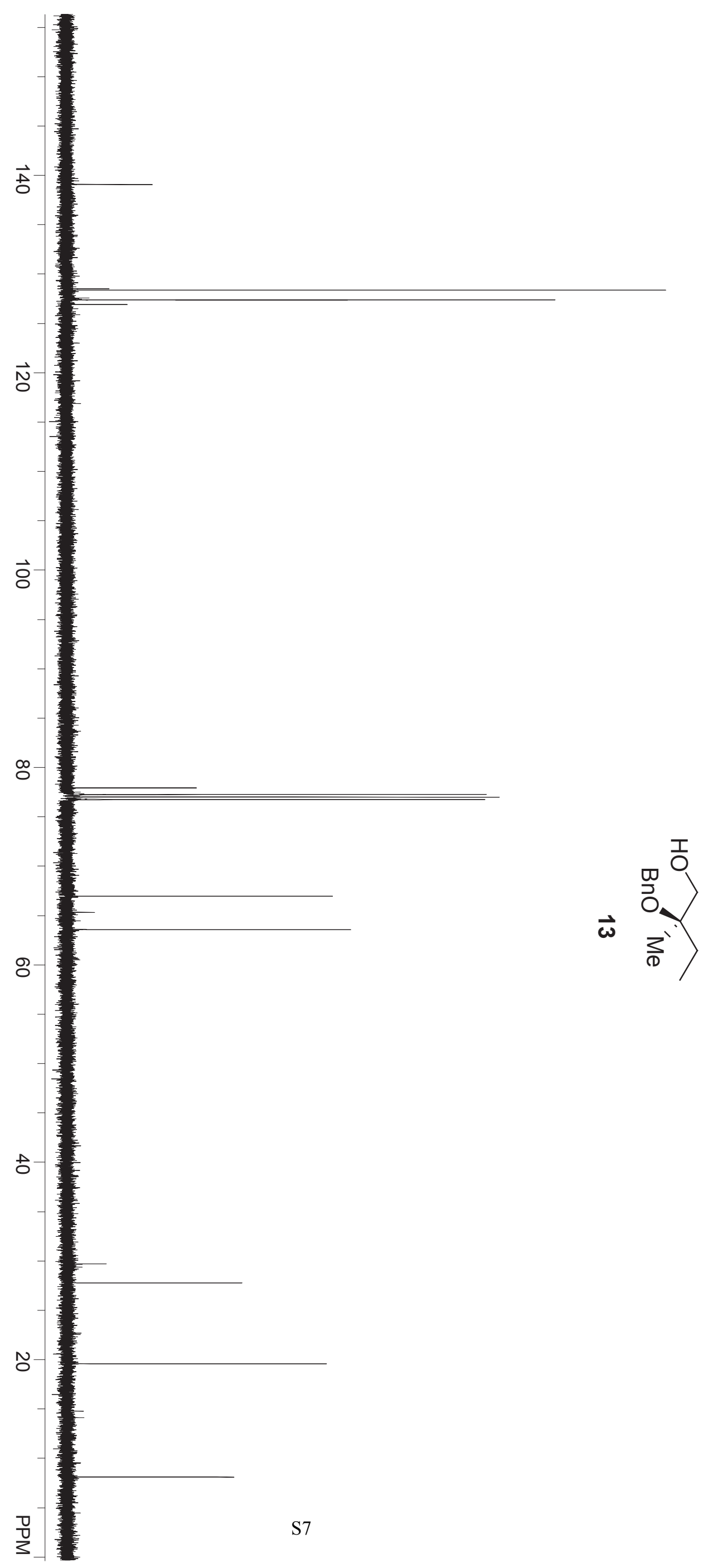




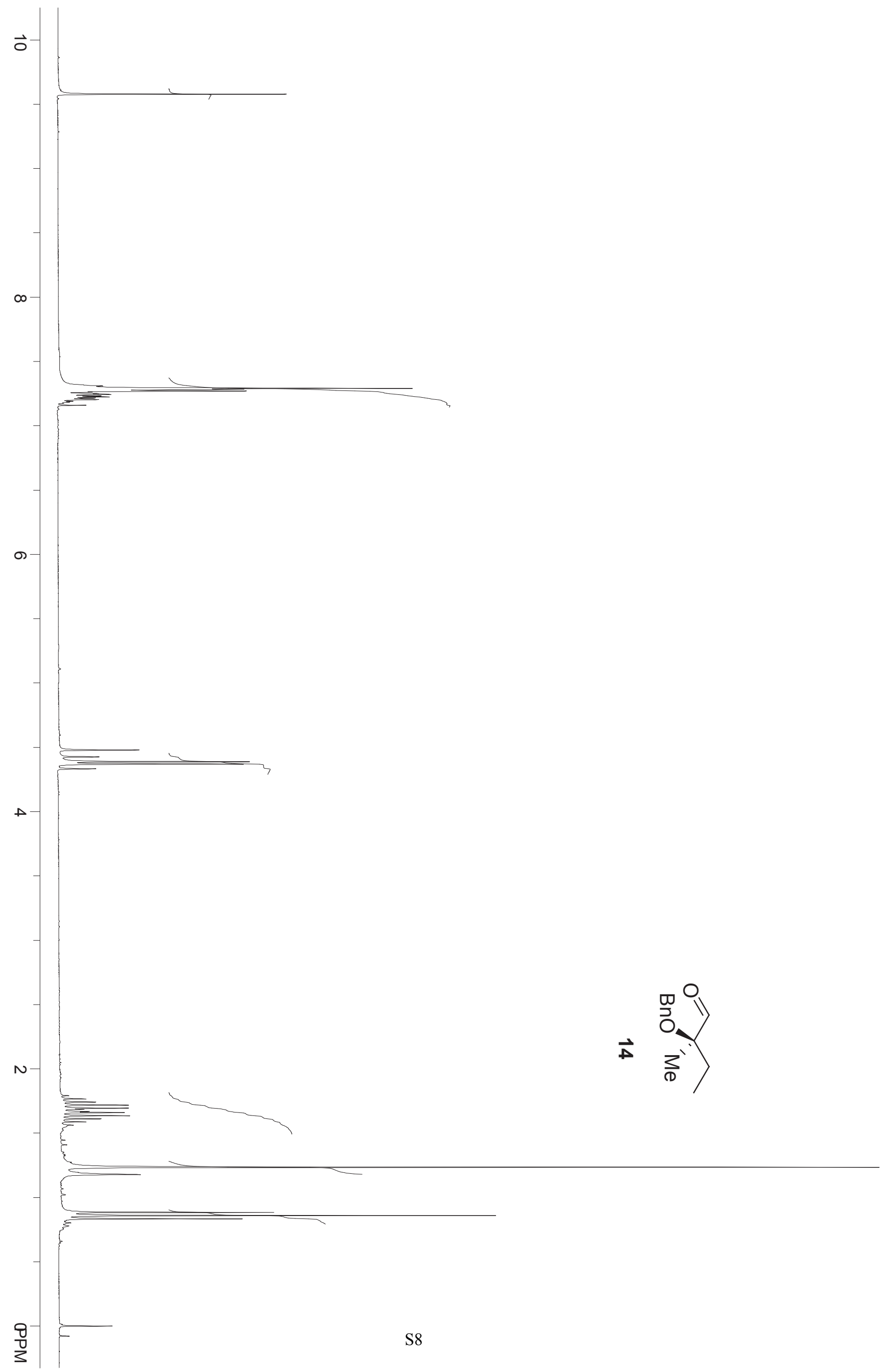




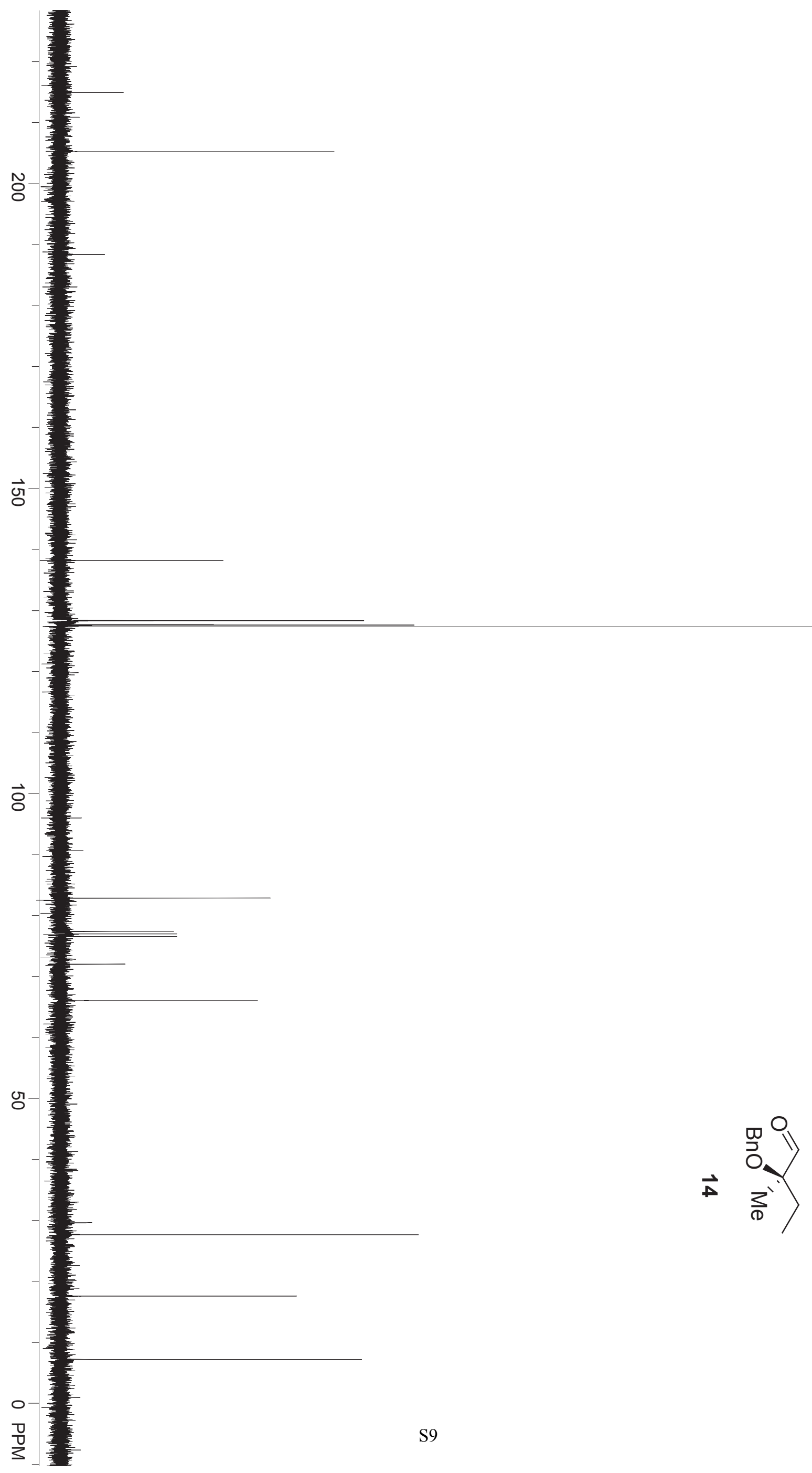




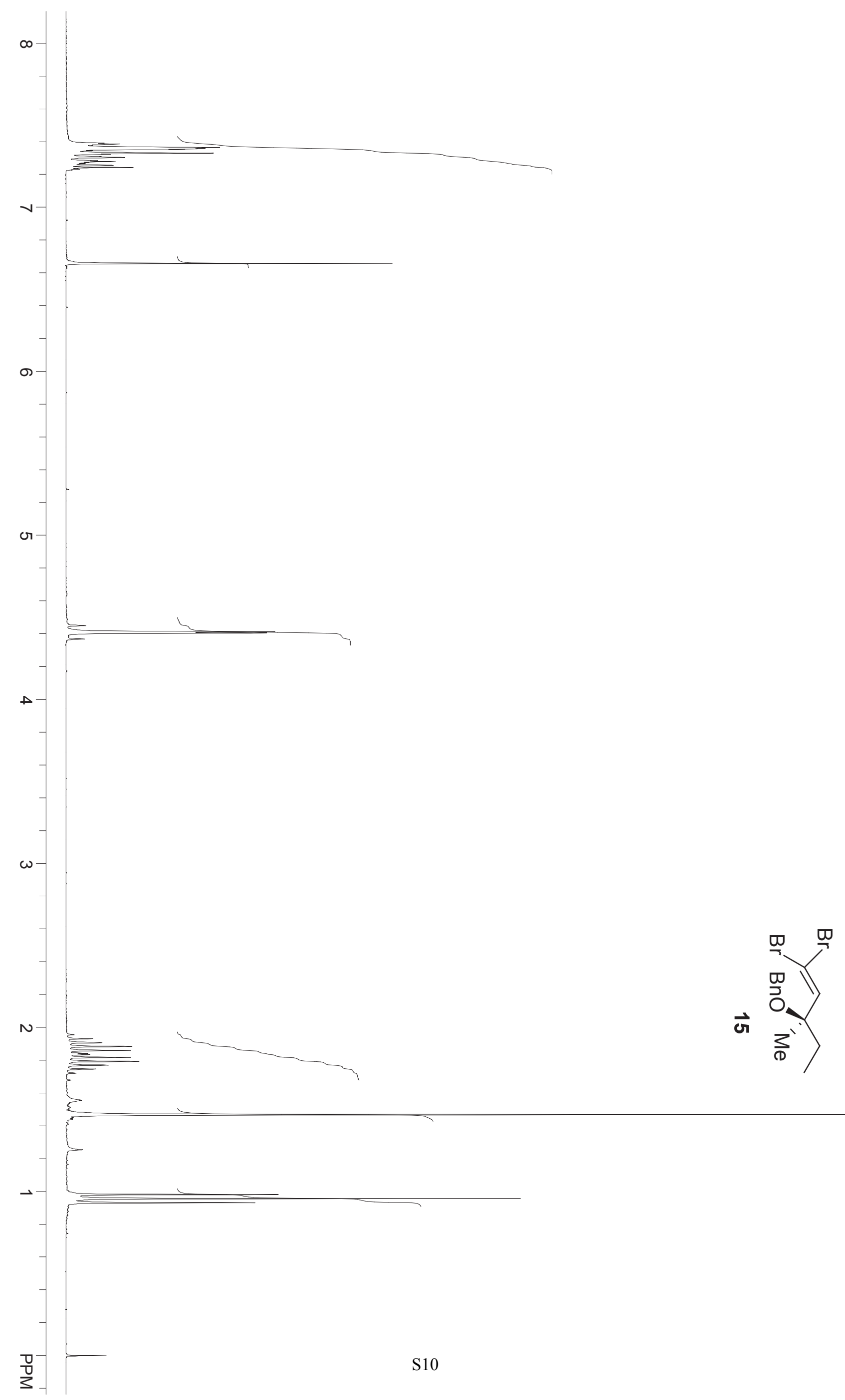




$$
\text { E. }
$$




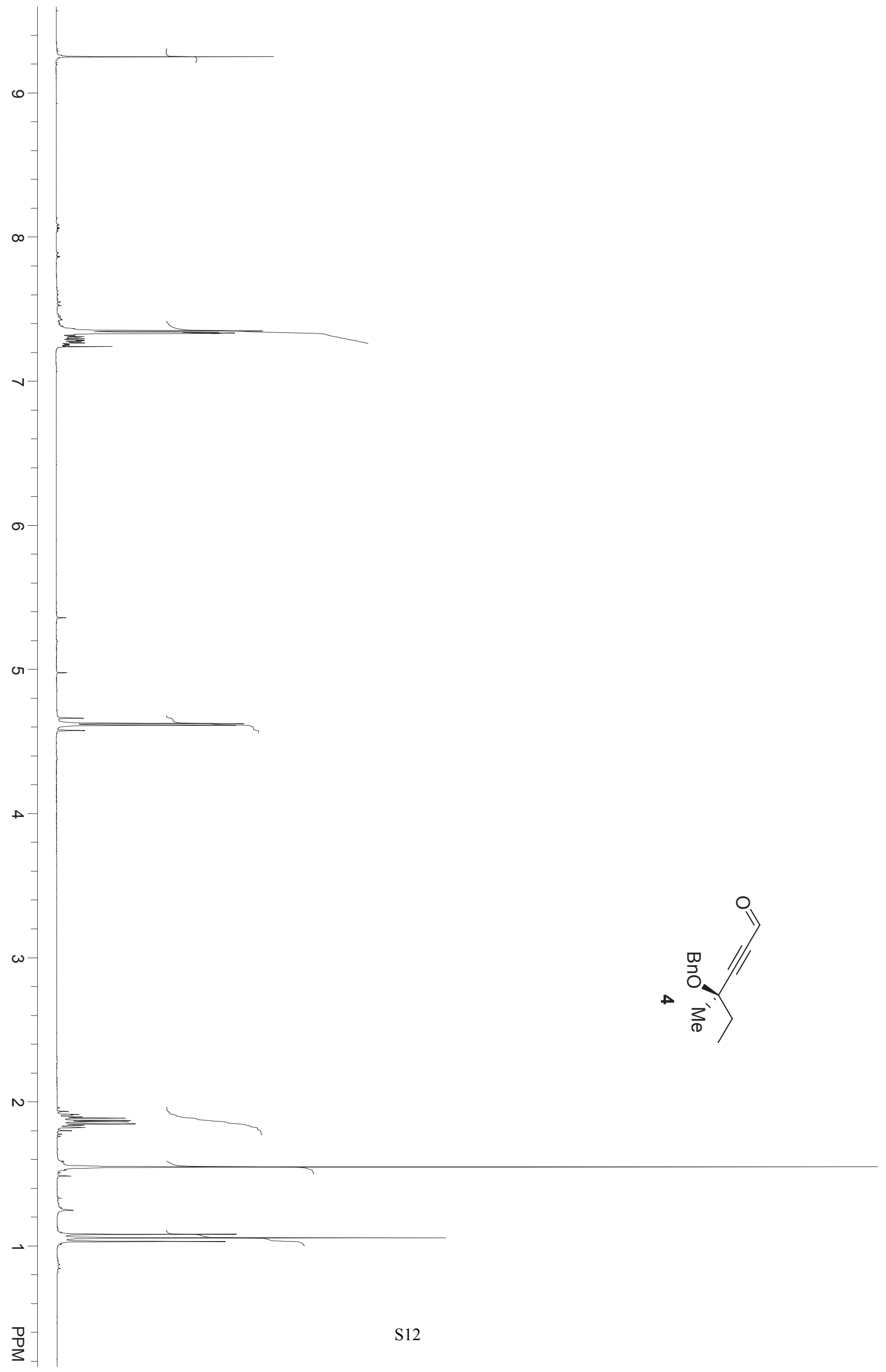



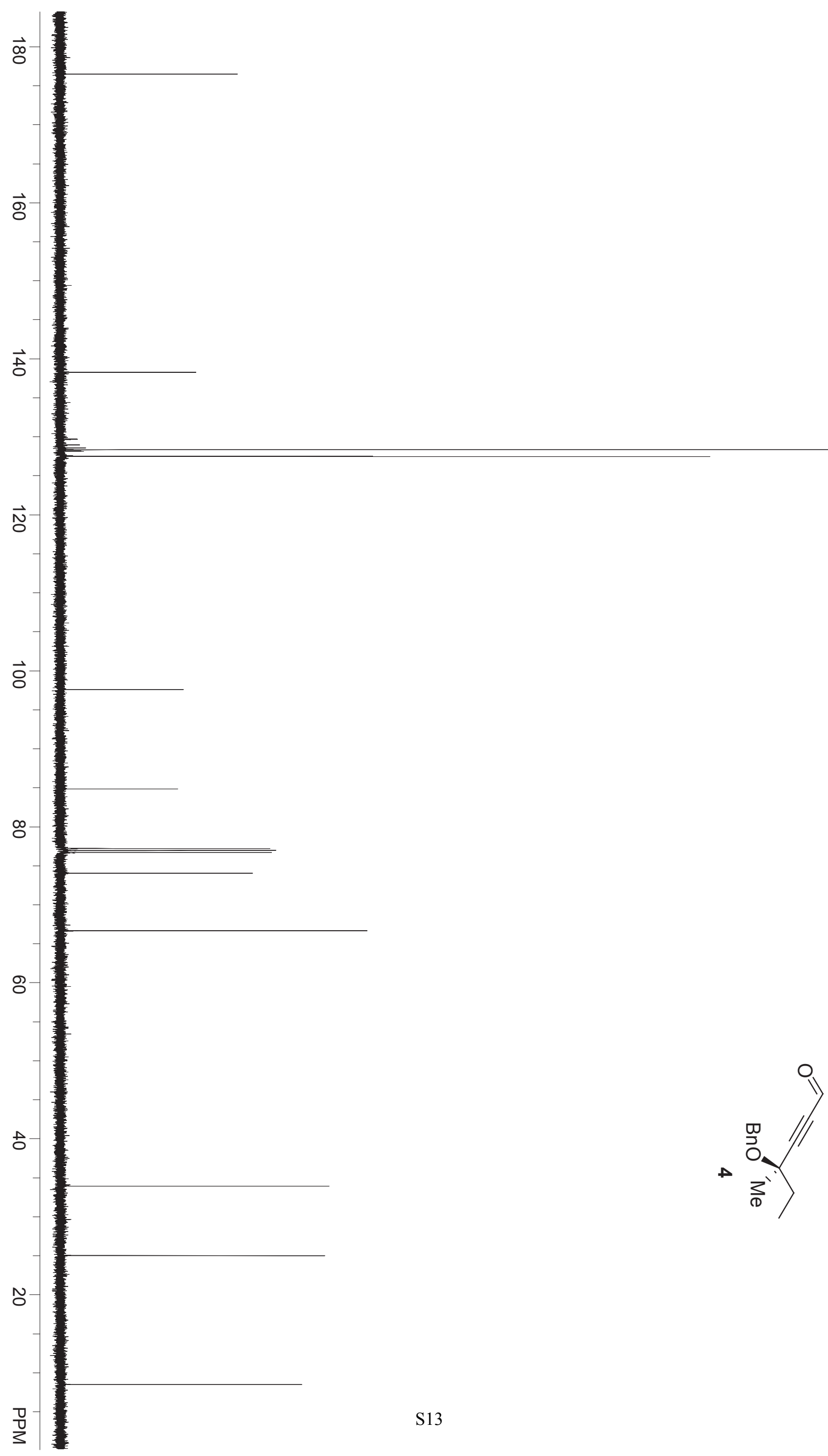


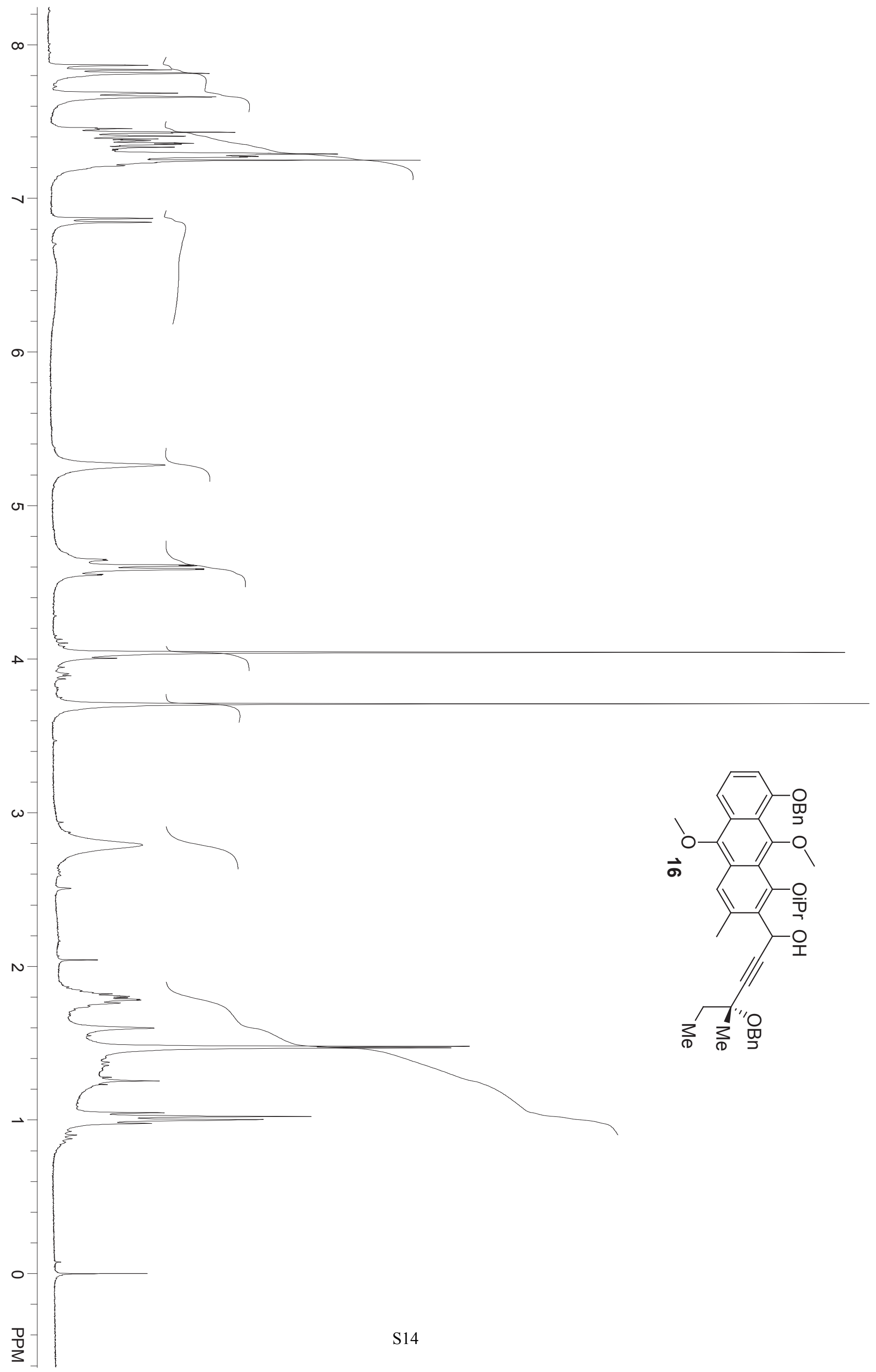




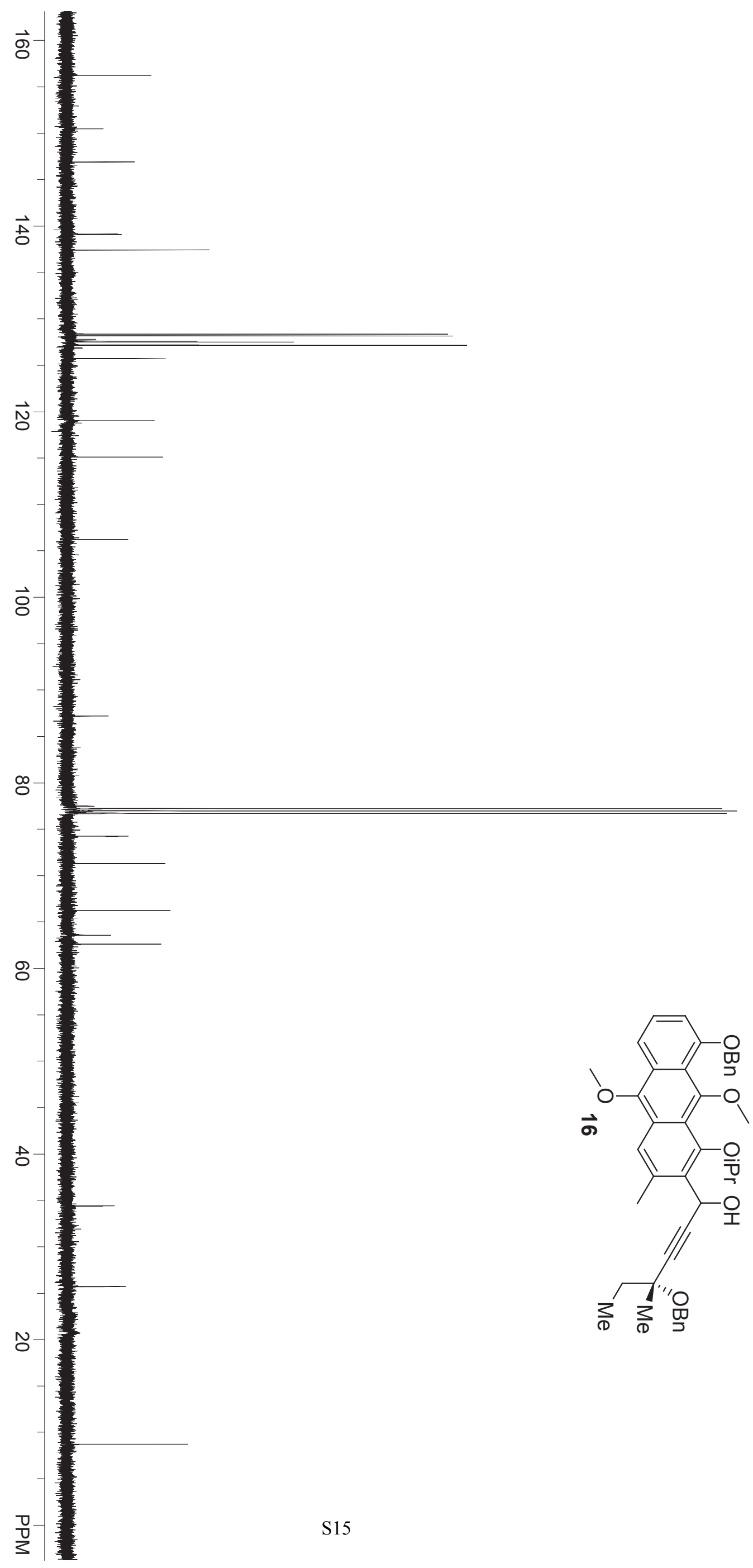




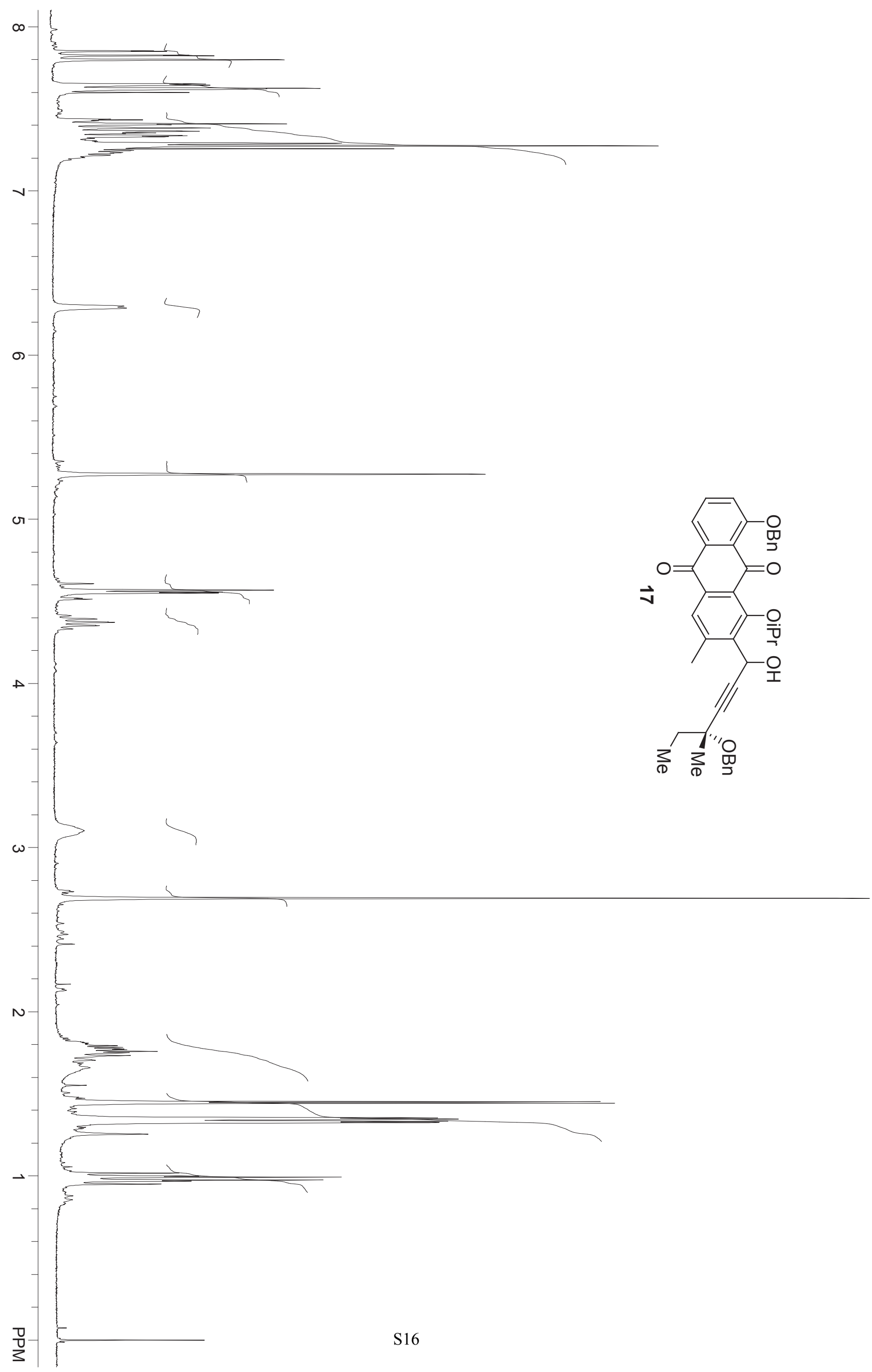




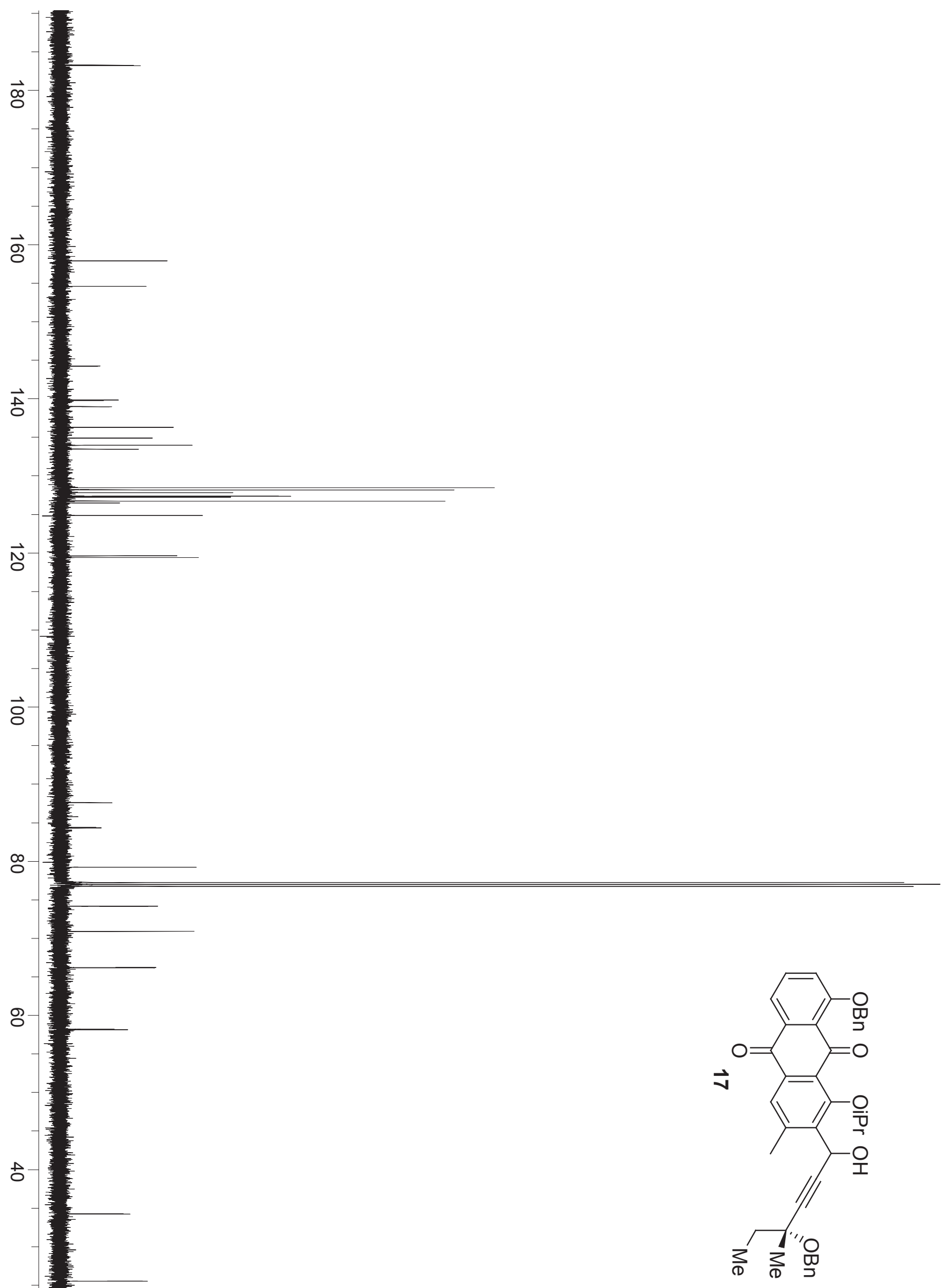

꾼 


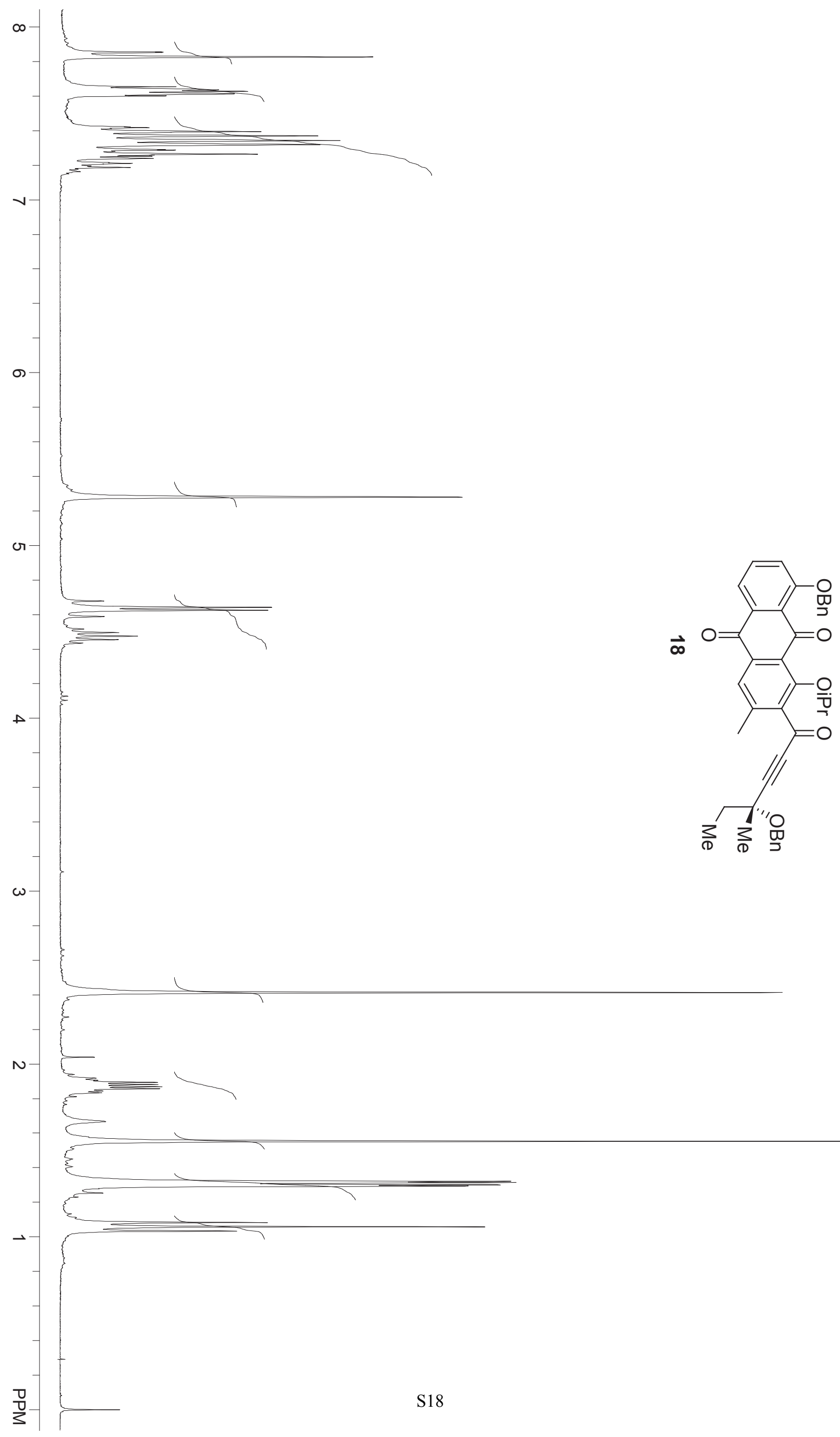




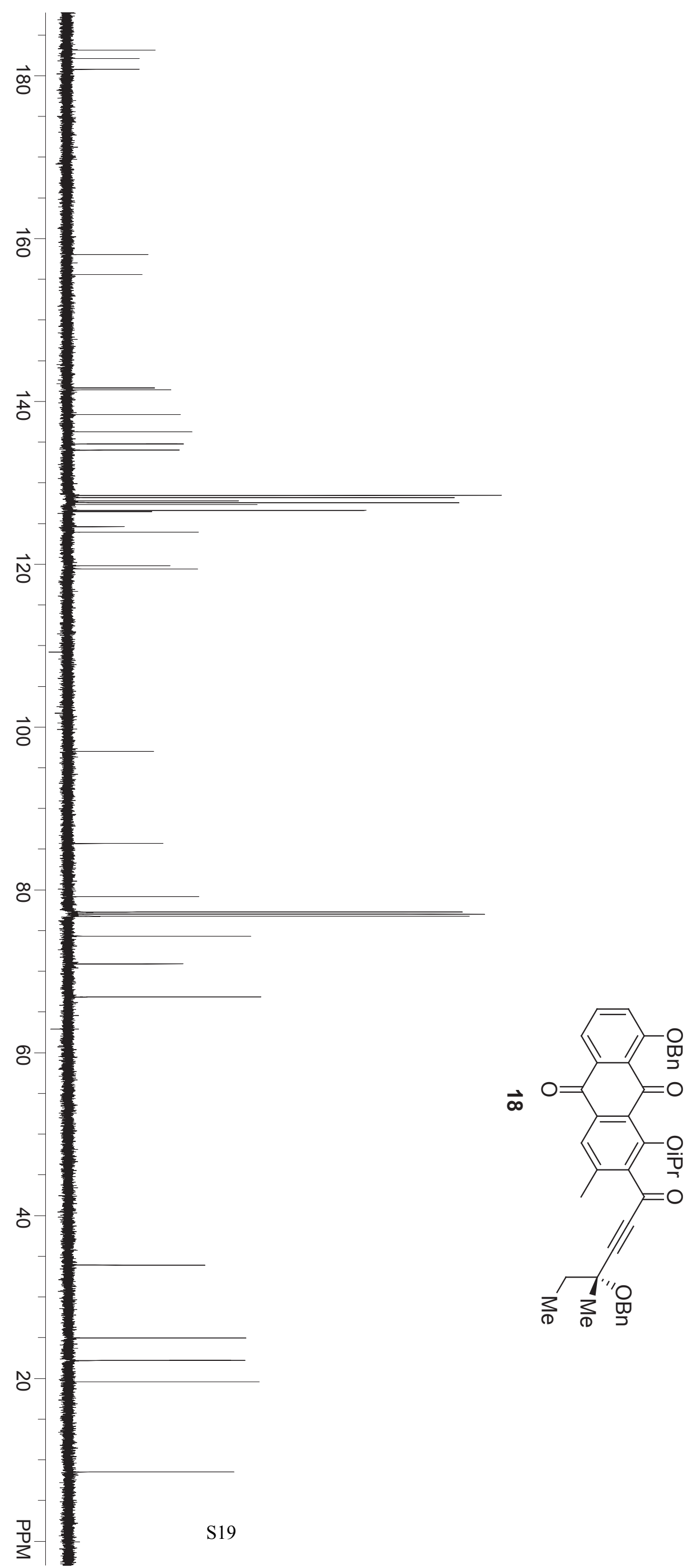




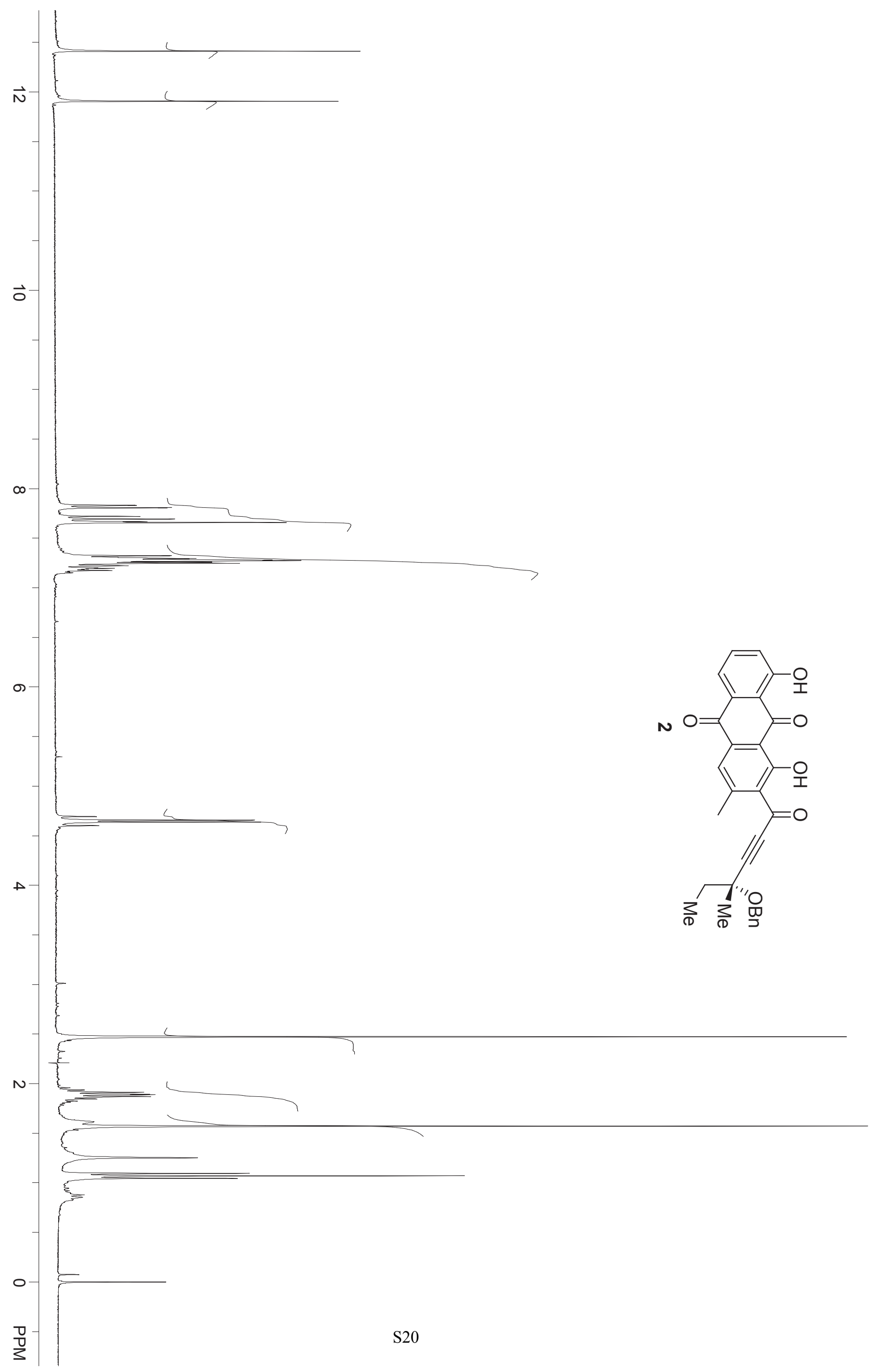




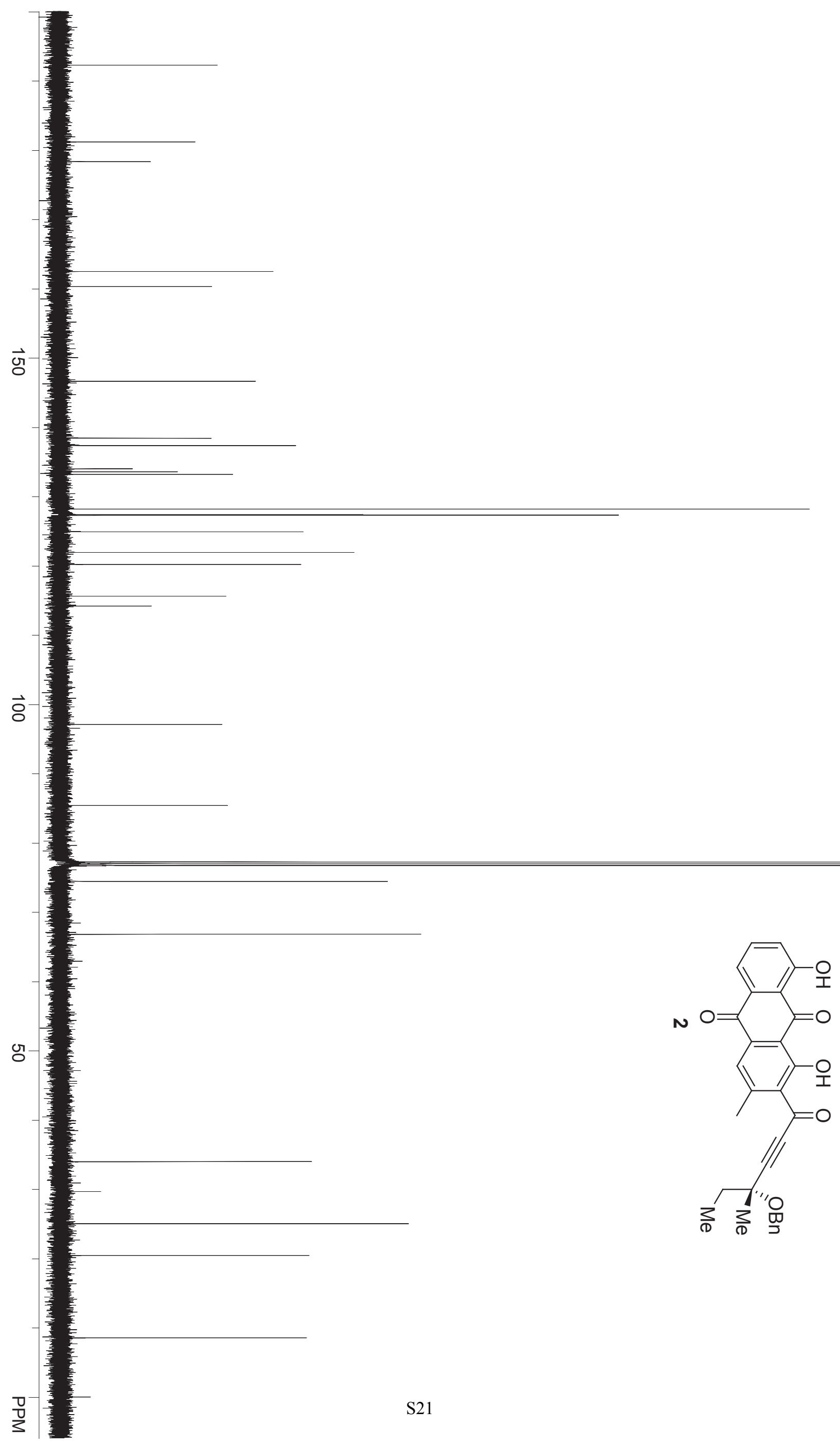




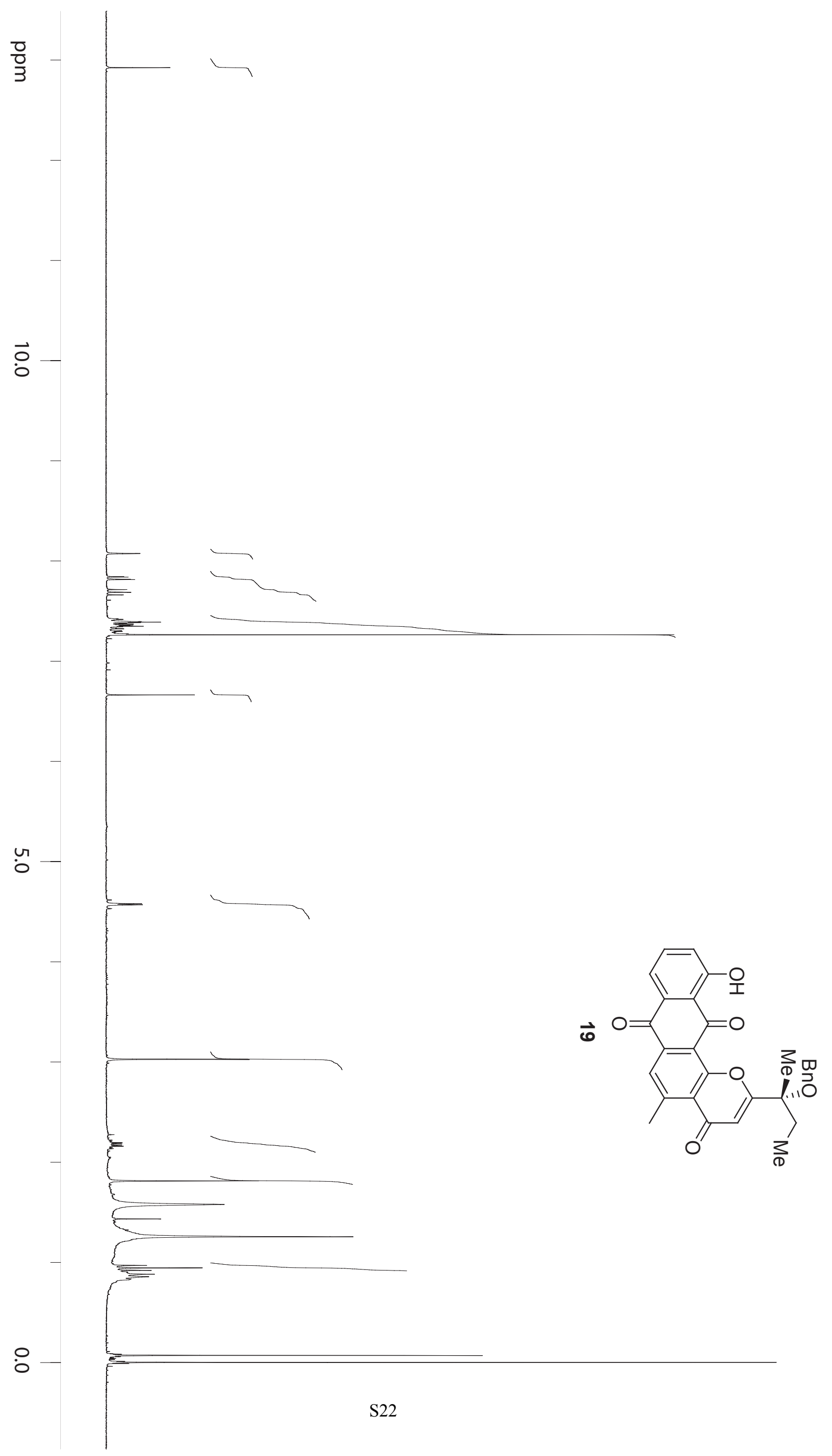




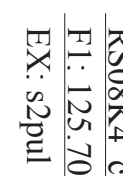

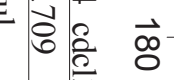

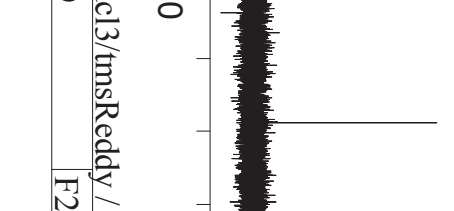

$\because$

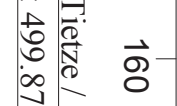

교

.

$\begin{array}{ll} & 0 \\ 3 & \\ 0 & \\ 0 & \\ 0 & \\ 0 & \\ 0 & \\ 0 & \end{array}$

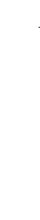

s

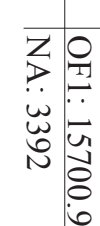

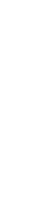

s.

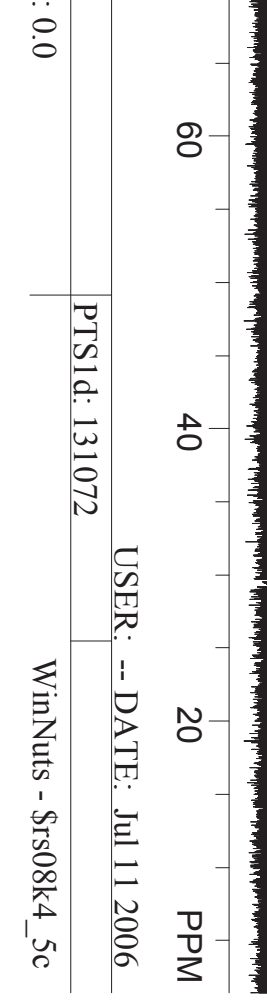




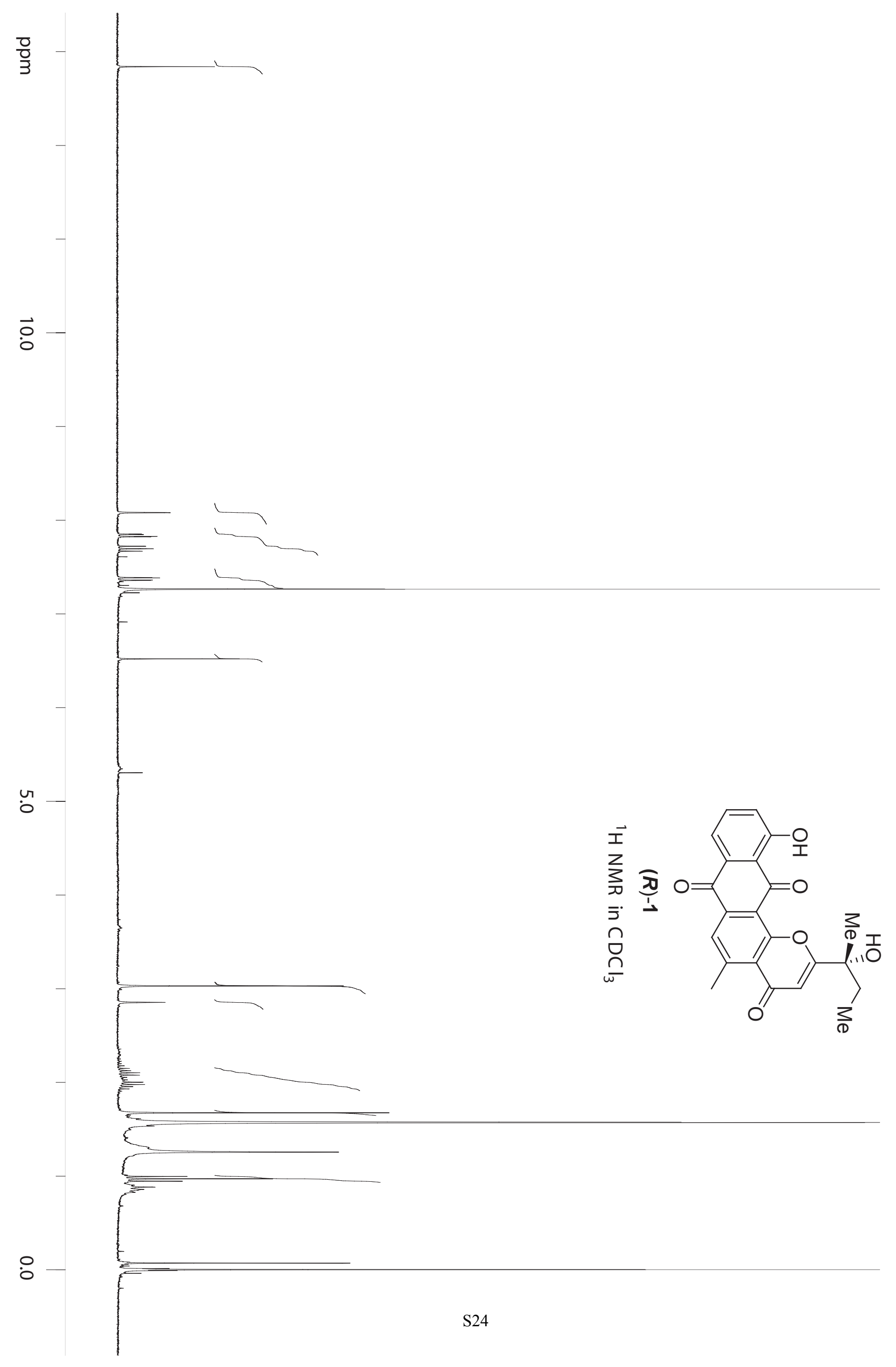




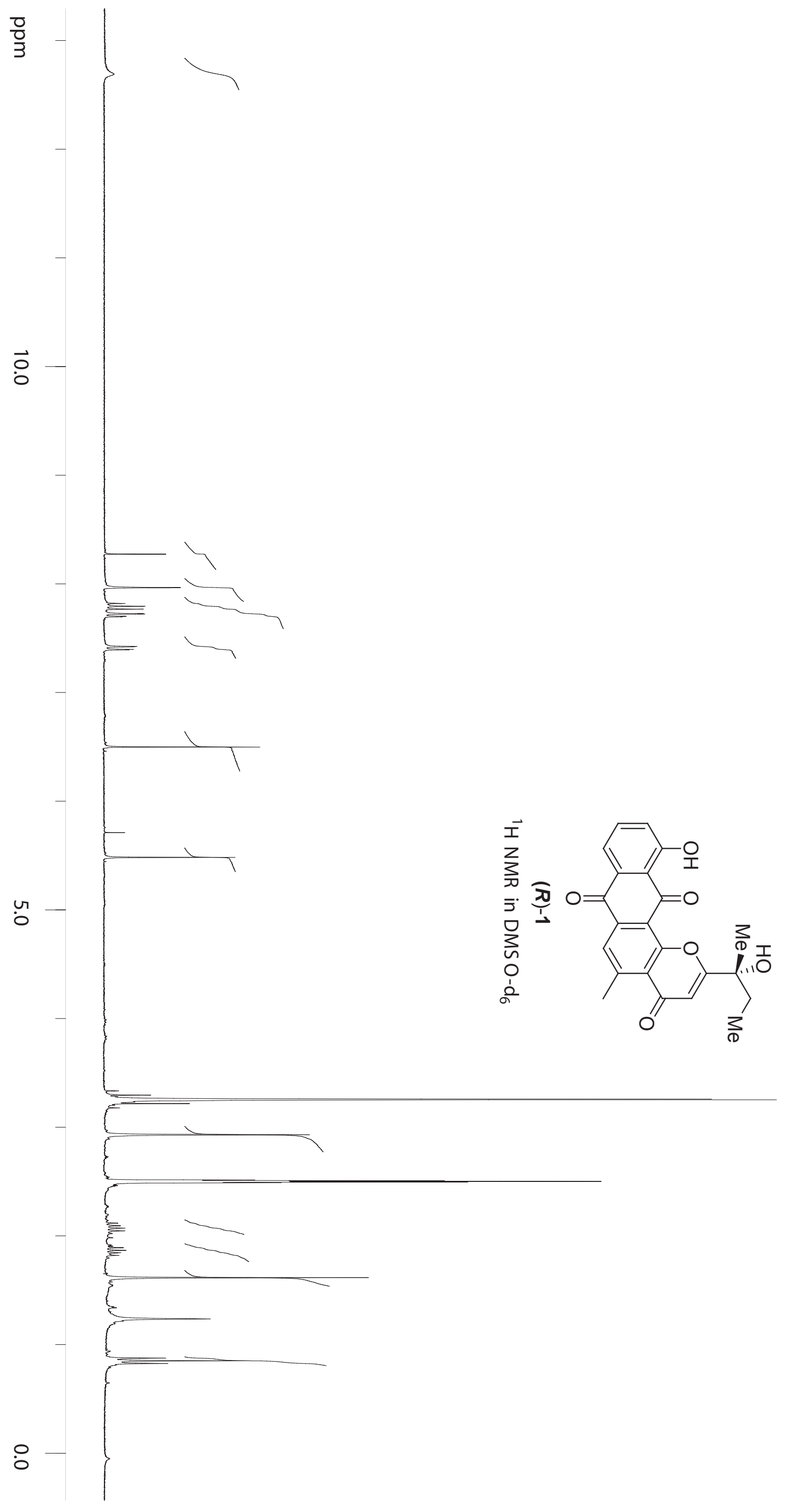




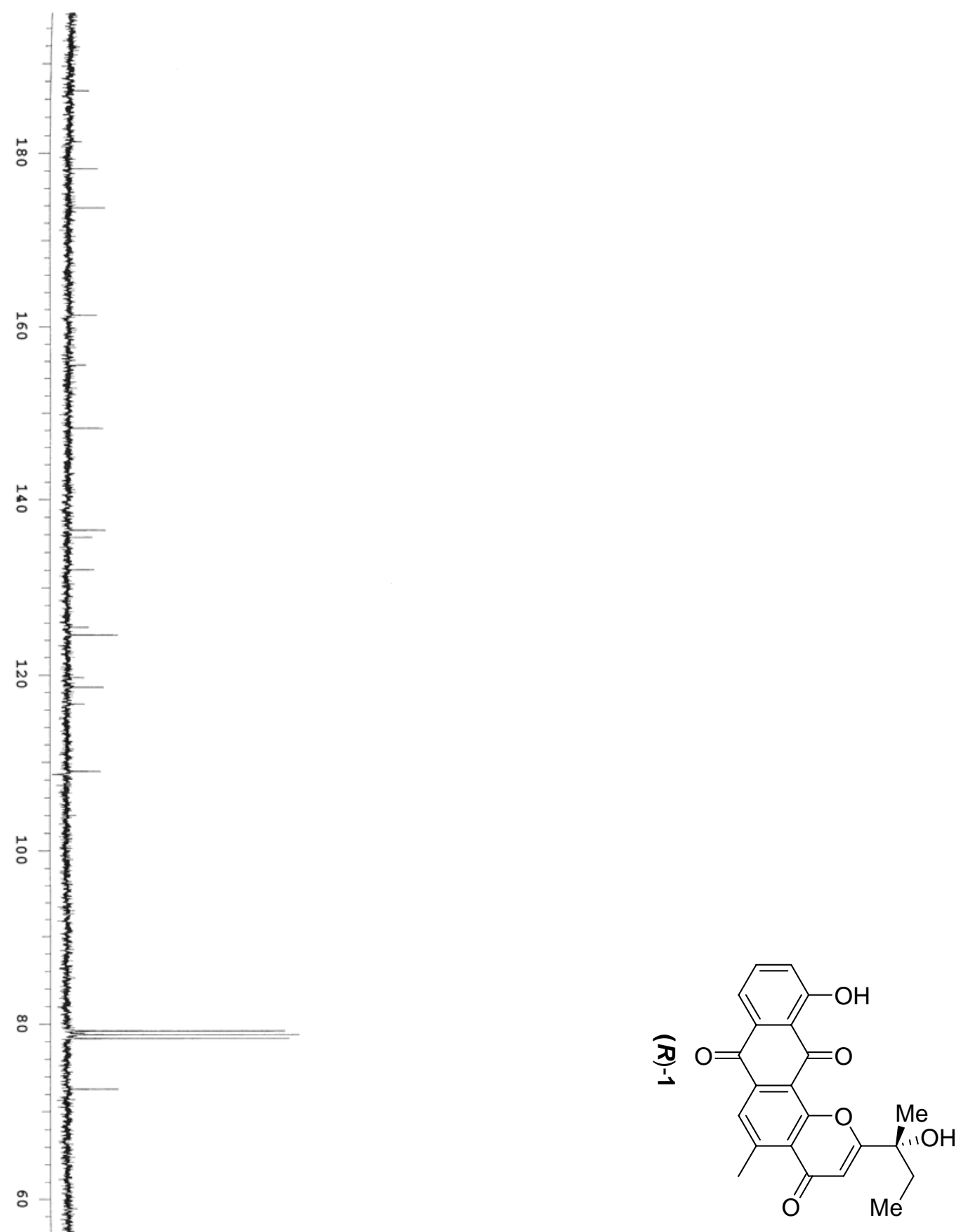

